Please quote as: Bretschneider, U. \& Leimeister, J. M. (2017): Not Just An Ego Trip: Exploring Backers' Motivation for Funding in Incentive-Based Crowdfunding. In: Journal of Strategic Information Systems (JSIS), Erscheinungsjahr/Year: 2017. 


\title{
Not just an ego-trip: Exploring backers' motivation for funding in incentive-based crowdfunding
}

\author{
Ulrich Bretschneider ${ }^{\mathrm{a}, *}$, Jan Marco Leimeister ${ }^{\mathrm{a}, \mathrm{b}}$ \\ ${ }^{a}$ Department of Information Systems, University of Kassel, Pfannkuchstr. 1, 34121 Kassel, Germany \\ ${ }^{\mathrm{b}}$ Institute of Information Management, University of St. Gallen, Unterer Graben 21, 9000 St. Gallen, Switzerland
}

\section{A R T I C L E I N F O}

\section{Article history:}

Received 16 June 2015

Received in revised form 20 January 2017

Accepted 6 February 2017

Available online $\mathrm{xxxx}$

\section{Keywords:}

Crowdfunding systems

Incentive-based crowdfunding

Motivation

Herding

Prosocial motives

Self-interest motives

Altruism

Recognition

Image

Lobbying

Liking

Social comparison

Reward

\begin{abstract}
A B S T R A C T
Incentive-based forms of crowdfunding - such as reward-, equity- and lending-based crowdfunding - are becoming increasingly popular. However, research that studies backers' motivations for funding in these environments is still in an embryonic state, revealing an inconsistent and narrow picture. The few existing studies are largely guided by the idea that backers are mainly egoistically motivated and do not have prosocial motives. We developed a research model that describes backers' motivation and conducted an empirical study to examine this model. Results indicate that backers indeed have several self-interest motivations for funding: prospect of a reward; expectation of recognition from others; to lobby a certain project in the hopes of its fruition; and to develop their image. However, some backers are also prosocially motivated in that they develop feelings of liking for a certain venture and/or project team. Furthermore, we found evidence that herding has a significant moderating effect on backers' reward motivation. Strategic IS researchers as well as crowdfunding practitioners can draw on our findings to systematically design, implement, and evaluate potential incentive systems that respond to reward-, recognition-, lobbying-, image- and liking-motives and thereby attract the crowd more effectively to invest in ventures presented on incentive-based crowdfunding systems.
\end{abstract}

(C) 2017 Elsevier B.V. All rights reserved.

\section{Introduction}

Crowdfunding is increasingly popular. Today, crowdfunding typically happens on the Internet with the help of what we refer to as crowdfunding systems. These strategic information systems are socio-technical systems that support interaction and connectivity between project creators, who launch certain projects and place open calls for funding these projects, and project backers, who want to financially support these ventures. The core elements of such systems are IT-based platforms that constitute the vital link between project creators and project backers.

One very young stream of crowdfunding research is focusing on investigating backers' motivation for funding. Insights on backers' motivation are highly relevant for information systems (IS) research, since it informs the design of web-based crowdfunding systems. Backers may be driven by several different motivations. By knowing which motivation leads to an investment, this information could help to systematically design tailored incentive systems that will stimulate these motivations and consequently lead to a funding.

\footnotetext{
* Corresponding author.

E-mail addresses: bretschneider@uni-kassel.de (U. Bretschneider), janmarco.leimeister@unisg.ch (J.M. Leimeister).

URL: http://www.wi-kassel.de (U. Bretschneider).
} 
When studying the motivation of backers, one has to take into account that crowdfunding encompasses four types of fundraising that range from collecting donations to selling equity stakes (Ahlers et al., 2012). In donation-based crowdfunding, backers donate money without expecting monetary compensation (Ahlers et al., 2012). In reward-based, lending-based, and equity-based crowdfunding, backers receive various forms of compensation. That is why we refer to these three forms as "incentive-based" crowdfunding. In this study we focus on the motivation of backers in incentive based crowdfunding.

Scholars examining backers' motivation in incentive-based crowdfunding are guided by the idea that backers seem to be mainly egoistically motivated and do not have prosocial motives. In their empirical work, Berglin and Strandberg (2013), Gerber and Hui (2013), as well as Ryu and Kim (2014) reported the following motives: "having fun", "Receiving a product or service", "being part of the community", "Interest", "Playfulness" and "Relationships to other people" (Berglin and Strandberg, 2013; Gerber and Hui, 2013; Ryu and Kim, 2014). These studies leave out considering prosocial motives, such as helping other, since it is believed that prosocial and self-interested motives involve mutually exclusive or opposing desire (Batson, 1998; Meglino and Korsgaard, 2004; Schwartz and Bardi, 2001). These ideological blinkers lead to an extremely narrow body of knowledge.

Another shortcoming of extant literature on this topic is that it presents motives that are already known from other domains, such as open source software communities. Therefore, these studies are criticized for having a too simple and generic perspective (Gierczak et al., 2015) as well as for lacking a more customized and focused view on the phenomenon of crowdfunding, thereby offering no new insights.

In summary, despite extant literature and even ongoing calls to investigate a crowd's motivation for participation in crowdfunding (Gierczak et al., 2015; Lehner, 2013; Moritz and Block, 2013), to date, a clear and consistent understanding of what motivates the crowd to invest in incentive-based projects is lacking.

Against this backdrop, this research aims to empirically investigate the crowd's motivation to fund incentive-based crowdfunding initiatives. We build a theoretical motivation model that considers both self-interested and prosocial motivation, allows for a more customized view on backers' motivation in incentive-based crowdfunding environments, and even proposes herding as a moderating effect that strengthens backers' reward motivation. To test our theory, we use a sample of over 300 backers on the incentive-based crowdfunding platform "Innovestment."

Our study offers a deeper and more precise understanding of the crowd's motivation for funding in the various forms of incentive-based crowdfunding and thereby contributes significantly to the currently sparse body of knowledge on this phenomenon. Furthermore, our results make major contributions to that stream of IS research that seeks to examine how human behaviors inform the design and use of web-based information systems. In the future, this stream of IS research may draw on our findings to systematically design, implement, and evaluate potential incentive systems that attract the crowd more effectively to invest in certain ventures.

\section{Extant literature}

Though the crowdfunding model in practice has achieved remarkable success and has emerged as a viable method of funding new ventures, to date, there has been very little scientific research on backers' motivation to fund projects in incentive-based crowdfunding. It is thus not surprising that the related literature on this topic is nascent and embryonic.

In their non-peer-reviewed working paper, Berglin and Strandberg (2013) conducted an online survey of 765 backers of three reward-based crowdfunding platforms. By using a small set of questions with each question representing one possible motive, they identified seven basic motives whose relevance was concluded from descriptive statistics. Based on the frequency of responses, they identified the most relevant backers' motivations as: "novelty", "fun", "being part of making it happen", "I am a fan of the project", "I fund for a good cause", "I have a personal connection to the project", and "receiving a product or service seems like a good deal". In their qualitative research, Gerber and Hui (2013) interviewed ten backers from three reward-based crowdfunding platforms. They identified motives such as "collect reward", "having fun", "be part of a community" (Gerber and Hui, 2013). Another study looked at motivations of backers' on a pure theoretical level. Ryu and Kim (2014) derived possible motives from prior literature on Internet-based communities and networks in which individuals produce a common creation, such as open source software communities. This work yielded only a few, non-validated motives: "having interest in the topic of crowdfunding", "playfulness", "receiving a reward", and "searching for social relationships".

It can be criticized that these motives are too general in nature and therefore could also be applied for studying motivations of participants from related domains, such as different forms of crowdsourcing initiatives or Internet communities. The same criticism also applies to most of the motives identified by the other two studies. Motives such as "I am a fan of the project" or "having fun" (Berglin and Strandberg, 2013; Gerber and Hui, 2013) seem to be justified in their respective studies, but they are too mundane, obvious, and generic and obviously are not derived from the specifics and characteristics of incentive-based crowdfunding. Therefore, they do not allow for a very customized and focused view on the phenomenon of motivation in incentive-based crowdfunding.

The list of motives introduced by the works of Berglin and Strandberg (2013), Gerber and Hui (2013), and Ryu and Kim (2014) have a further shortcoming: they suggest that backers in incentive-based crowdfunding initiatives are mainly egoistically motivated and do not show a tendency of having prosocial motives. Scholars currently assume that the two 
positions are mutually exclusive. However, as insights from research on human motivation teaches us, prosocial and selfinterested motives are independent and can even co-exist within individuals (De Dreu and Nauta, 2009). It can be assumed that this is also the case in incentive-based crowdfunding. However, the current body of knowledge does not consider this.

Although the motives proposed by the three studies (summarized in the section titled "Literature Review") provide an initial insight into the motivations of backers of incentive-based crowdfunding initiatives, their shortcomings lead to an incomplete and too narrow picture. Therefore, there are ongoing calls to further investigate the motivation for participation in crowdfunding (Lehner, 2013; Moritz and Block, 2013). In this study, we refine and clarify the picture by firstly investigating more customized motives, by not only considering self-interested motivation factors, but also prosocial ones and by examining herd phenomenon as a strengthener of backers' motivation instead of considering it as a motive.

\section{Theory development and hypotheses}

Motivation psychology differentiates between "motive" and "motivation." A motive is seen as an individually developed and content-specific psychological disposition (Deci and Ryan, 1985). Some motives are inborn, while a relatively stable set of motives is developed during an individual's socialization process (Deci and Ryan, 1985). Motivation describes the process of how an individual's motives become activated and lead to a behavior. In other words, motivation is the energization of behavior (Deci and Ryan, 1985). A certain situational context, that an individual perceives, serves as an incentive or impulse that starts this process, meaning this incentive or impulse stimulates corresponding motives (Schater, 2011). Adapted to the crowdfunding case, the situational context could be an offered return from a project. As described, this incentive stimulates a backer's reward motive. This activated motive then subsequently causes a certain behavior, meaning in the context of crowdfunding that a backer invests in a certain project. This motivation process, in particular the relationship between activated motives and behavior, constitutes the architecture for developing our hypotheses.

In each of the following sub-sections we introduce one characteristic of incentive-based crowdfunding. From each of these characteristics we theoretically derive one possible motive. This allows for selecting specific motivations of backers in incentive-based crowdfunding.

\section{Backers' personal connections to projects}

Backers in incentive-based crowdfunding environments are said to have different forms of personal connections to project creators and/or project causes (Moysidou, 2016). This personal connection sometimes results from congruency between the crowdfunding project and backers' personal beliefs and likes (Moysidou, 2016). Furthermore, Lin and Viswanathan (2016) confirmed that backers sometimes have a personal connection because of a geographic proximity between the project creator/the project cause and the backer. Furthermore, due to home bias, backers are expected to have personal connections for projects which refer to a society or region they feel close to, either because it is the one they live in or one they share values, cultural or religious background, etc. with (Lin and Viswanathan, 2016; Moysidou, 2016). Agrawal et al. (2015) found that having friends and family as supporters of a crowdfunding project is another source of personal connections between backer and project creator.

Because of this personal connection to a project creator or a project idea backers evaluate the appropriate project in a generally positive way (Moysidou, 2016). We believe that under this circumstance backers might behave altruistically, which is referred to as "doing something for another at some cost to oneself" and can be interpreted as the direct opposite to selfishness (Ozinga, 1999). Research on motivation psychology confirms that one condition under which individuals develop altruistic motives is a personal connection (Batson et al., 1988), which means that if a person has a personal connection to another individual then this person will develop an altruistic motive in relation to this individual as a contentspecific, psychological disposition (Batson et al., 1988).

This form of altruism is also discussed as a prominent motive in different motivation studies seeking to investigate why users contribute to different forms of online communities. For example, Hars and Ou (2002) as well as Lakhani and Wolf (2005) empirically validate that open source software developers who are motivated by altruism seek to help the open source community by enhancing existing software codes or developing new ones at their own cost and without expecting any reward. Their individual altruism motive has been developed because of their personal connection to the open source community's fundamentals beliefs and promotion of computer users' right to use, study, copy, modify, and redistribute computer programs. The same applies to the phenomenon of Wikipedia. With the help of empirical studies, scholars have found that individuals' motivation for writing and editing articles for Wikipedia for the good of others is grounded in their altruism motive, which they have developed because these people deeply agree with Wikipedia's fundamental principles (Benkler and Nissenbaum, 2006; Nov, 2007).

Against this backdrop, we propose that backers in incentive-based forms of crowdfunding will likely fund because of their altruistic motivation. Thus, we hypothesize: 
H1. In an incentive-based crowdfunding context, backers' altruism motivation is positively associated with investment.

\section{Comment functionality on crowdfunding systems}

Crowdfunding systems for incentive-based crowdfunding typically consist of a set of related web pages, one of which is the project page. This page is showing detailed information about a project. One major element on this project page is the comment functionality, which is intensively used by backers and users to express best wishes for the project, to discuss the project with other users or to ask questions about the project. This comment functionality is also used by project creators and other backers to thank, to praise and to recognize backers for funding.

This leads us to the motivation of recognition. In psychology research, recognition is referred to as acknowledgement of an individual's status, achievements, or merit (Maslow, 1987; Nerdinger, 2006). According to Maslow (1987), recognition is derived from individuals' inner desire for fame and esteem. Recognition can be implicit or explicit (Nerdinger, 2006). For example, implicit recognition takes place when a scientist's work is cited in the paper of another scientist. Psychologists speak of explicit recognition, for example, when one person praises another person for an achievement (Nerdinger, 2006). Recognition can be provided by a person, group, or organization.

Recognition is prominently investigated in the context of motivation of programmers engaging in open source communities. For example, Hars and Ou (2002) reveal that software programmers' desire for receiving recognition by other programmers is a significant motive for participation in open source communities. Peer recognition in open source communities can appear in form of implicit recognition; for example, when other programmers use software codes of other programmers (Hars and Ou, 2002). It also appears in explicit form when peers provide positive feedback to programmers' contributing software codes (Hars and Ou, 2002). In general, feedback culture in open source communities is very mature. According to Raymond (2001), open source programmers receive rapid and constructive feedback on the quality of their composition. This constitutes an ideal feeding ground for recognition motivation that leads to higher level of participation and engagement in open source communities.

We believe that the motivation of recognition plays also a vital role in incentive-based crowdfunding. As mentioned other project backers and more often project creators use the comment functionality of crowdfunding websites to thank, praise, and recognize backers for their funding. Against this background, we propose that backers might fund in expectation of positive reactions from other backers or the project creator because of their financial contributions. This leads to our next hypothesis:

H2. In an incentive-based crowdfunding context, backers' recognition motivation is positively associated with investment.

\section{User profile Webpages on crowdfunding systems}

Another key page of crowdfunding systems is the user profile webpage (UPW), which is known from professional social networking platforms, such as "Linkedin”, “Facebook”, and other virtual communities. The UPW not only displays a backer's basic information, such as their name or photo, but also information on how many projects the backer has already funded and sometimes even information on the amount of money he/she has already funded. Furthermore, the already mentioned project pages include a list of backers who already have funded the project. These lists prominently display each funder by his/her name.

We believe that UPWs as well as the mentioned list of backers are used by some backers to create an online image on crowdfunding systems and that their desire for creating such an online image leads them to fund projects. In general, IS research scholars found that members of virtual communities actively create an image explicitly for the virtual environment, which supports the argument that individuals care about their status not only in the real world, but also in the virtual world (Jabr et al., 2014). For example, the fact that in offline settings effective social interaction does not occur if people do not construct and present their identities (Goffman, 1959) inspired IS scholars to investigate image as an important motive for participation in social network websites, such as LinkedIn or Facebook (Ma and Agarwal, 2007). Kim et al. (2011) found that in social network communities, members' desire for an online image even serves as a motivation for the purchase of digital items, such as avatars and decorative objects, that in turn help to create an image. In the open source context, the image motive is referred to as the reputation motive and also plays an important role. Lerner and Tirole (2002) highlight the desire for reputation as a key driver for programmers' engagement in open source projects.

Against this background, we propose that the image motive can also play a role in the context of incentive-based crowdfunding. Backers may be driven by their online image concerns to fund. Since each funding is documented and displayed together with the backers' name on their UPWs, the act of funding a project enables backers to associate themselves with those fundings and, in turn, makes their online selves more attractive. This means that this behavior may be used to create a preferred image on crowdfunding websites. Therefore, backers' desire for an online image could be a motivation for backers to fund. Hence, the above discussion leads us to develop the following hypothesis: 
H3. In an incentive-based crowdfunding context, backers' image motivation is positively associated with investment.

\section{Backers' needs}

In literature on crowdfunding backers are seen as rationally acting individuals seeking to maximize their benefits and satisfaction; i.e., backers are thought to be individuals who develop personal needs on the basis of projects presented on a crowdfunding system (Moysidou, 2016). In other words, when backers regard a project as personally relevant and consistent with their values and goals, they will develop a personal need (Moysidou, 2016; Ordanini et al., 2011; Schwienbacher and Larralde, 2012). So, the generation and creation of needs play a central role in incentive-based crowdfunding.

Against this background, we propose that backers contribute financially in order to increase the chances that this project will collect the necessary capital and the project outcome will be realized. So, the idea here is that a project's underlying concept (be it prototype service/product, idea, or even start-up) does not yet exist in the market and therefore backers try to ensure its success through their engagement. In other words, backers hope that the project is realized since it reflects their personal need.

This motivation has also been evidenced in the open innovation context. Bretschneider et al. (2015) empirically investigated customer motivations for participation in firm-initiated ideation of new product development (NPD). They found that customers feel that through their participation they can lobby and influence the firm to incorporate certain product features that are highly valuable to them and reflect a personal need (Bretschneider et al., 2015). This particularly holds true for the enterprise software product market, where customers actively contribute to product development efforts in order to ensure that their specific needs are met by a new product (Hoch and Roeding, 1999).

We believe that this mechanism can be transferred to the context of incentive-based crowdfunding. So, backers in these forms of crowdfunding are likely to fund, lobby for, and influence a project in the hope that it will collect the necessary capital and the project outcome will be realized. We refer to this as the lobbying motivation and hypothesize:

H4. In an incentive-based crowdfunding context, backers' lobbying motivation is positively associated with investment.

\section{Project description on crowdfunding systems}

The mentioned project pages on crowdfunding systems also display a description of a project. This project description includes information on why the project creator launched this project, the project goal and outcome, the runtime of the project, personal information about the project creator, etc. Nearly all project descriptions include short videos featuring and praising the project in an audiovisual manner. Crowdfunding literature says that this information provides a solid basis for developing feelings of liking a project (Moysidou, 2016; Ordanini et al., 2011; Schwienbacher and Larralde, 2012).

In general, liking - as a feeling of liking a person or an object - is covered by various scientific investigations that aim at researching individuals' affections for someone or something. In the 1990s, scholars from marketing science used this term to measure consumers' affection for advertisements (Unger et al., 1995). In the same decade, when computers became more and more relevant in business world, IS research began to investigate a phenomenon called computer attitude: This stream of IS research sought to investigate users' attitude toward computers as a critical factor in enhancing the acceptance of computers as well as understanding current user behavior and shaping future behavior, such as computer usage (Al-Jabri and AlKhaldi, 1997; Henderson et al., 1995). In that time, three types of computer attitudes became apparent: anxiety or fear of computers; confidence working with computers; and computer liking (Al-Jabri and Al-Khaldi, 1997; Henderson et al., 1995). From that time, liking more and more became a relevant and validated construct in IS research on user acceptance, both as a sub-construct of computer attitude and as a standalone construct. For example, in her study Broos (2005) investigated computer and Internet liking in women and men. Kang and Kim (Kang and Kim, 2006) investigated the influence of web pages content on Internet users' attitude, where liking was investigated as a sub construct of attitude. Sabherwal et al. (2006) found liking to be a determinant of information systems success. Liking as a sub-construct of attitude plays also a relevant role in examining online shopping behavior of Internet users. For example, Pavlou and Fygenson (2006) investigated the motivational effect of liking in online shopping environments, finding that users' liking of an online shop's offer influences users to shop there. Studies from Korzaan (2003) and Lian and Lin (2008) revealed similar results.

In general, persons who produce feelings of liking seem to use this feeling to make decisions, which is why liking plays an important role in explaining human behavior (Clark, 2010). Scholars in the field of motivation psychology have investigated the motivational effect of liking in offline environments. For example, in the field of business angels investing in start-ups, liking plays a relevant role. Brettel (2003), Feeney et al. (1999), and Mason and Stark (2004) submit that liking in the form of a likeable impression and a certain personal appeal toward entrepreneurs and their ventures is the first step to a potential investment in their business. Against this background, we believe that liking may also be an important motive in our context. We assume that backers may invest in a certain project because they like the project. Regarding the development of liking, project creators' project pages with their detailed information and videos on the projects play an eminent role, since this medium transports personalized or even touching information and details about a project. Such information and details are considered as the feeding ground for developing feelings of liking. Hence, we hypothesize: 
H5. In an incentive-based crowdfunding context, backers' liking motivation is positively associated with investment.

\section{List of funders on crowdfunding systems}

We already introduced the list of backers that are prominently featured on the project pages of crowdfunding systems. These lists register each funder by his/her name. We believe that such lists could incite backers to fall for the phenomenon of social comparison. Social comparison refers to the inborn desire of individuals to evaluate their own options and abilities by comparing themselves to others (Festinger, 1954). Festinger, who initially defined this concept in the social comparison theory, states that individuals base their comparison against others in a competitive setting (Chen and Garcia, 2010; Festinger, 1954). "These social comparisons throw light on any discrepancies with the target rival, and motivates the individual to behave in a competitive manner, aimed at reducing or eliminating such discrepancies that might be damaging to one's ego" (Chen and Garcia, 2010). For example, individuals are willing to exert more costly effort and expand resources in order to avoid falling behind the average performer or to improve an attribute because they wish to rank highly within their perceived peer groups (Ball and Eckel, 1998). Social comparison theory has also been applied to explain social behavior. For example, people are more willing to contribute toward a social cause when others also contribute; i.e., these individuals try to match the allocations of their counterparts (Frey and Meier, 2004).

People's tendency toward social comparison may also hold true in the context of incentive-based crowdsourcing. We propose that backers - in case they perceive that other backers have already funded a particular project - may be willing to also fund that project in order to not fall behind their "counterparts". The social comparison required in this context can occur through the mentioned list of backers. Based on this, we hypothesize:

H6. In an incentive-based crowdfunding context, backers' social comparison motivation is positively associated with investment.

\section{Anticipation of reward}

In reward-based crowdfunding backers receive non-financial benefits in exchange for their investment (Ahlers et al., 2012), ranging from signed autograph cards from celebrities to pre-orders, early access to products, and discounts on products. In lending- and equity-based crowdfunding, backers receive monetary returns in the form of a fixed periodic income and expect repayment of principal or some form of equity or equity-like arrangements (e.g., profit-sharing) from the venture they supported (Ahlers et al., 2012).

It is to be expected that the main and obvious motivation to fund in all forms of incentive-based crowdfunding will be a reward. In particular in equity-based crowdfunding, the motivation to participate is comparable to that of business angels. One obvious explanation of why business angels invest in a start-up is the overriding goal of obtaining profit and/or capital gains on the invested capital (Feeney et al., 1999).

This extrinsic reward motivation draws on the incentive theory, which is one of the major theories of motivation, asserting that behavior is motivated by a desire for reinforcement or incentives. It proposes that behavior is motivated by external goals, such as reward or money (Hockenbury and Hockenbury, 2003).

We believe reward motivation also plays a significant role in incentive-based crowdfunding, since backers can expect rewards if a certain venture is successfully funded. Hence, we hypothesize:

H7. In an incentive-based crowdfunding context, backers' reward motivation is positively associated with investment.

\section{Backers' uncertainty and herding behavior}

Literature describes that in incentive-based forms of crowdfunding there are high levels of uncertainty for backers when they have to decide whether or not to invest in a project. Uncertainty results from backers insecurity about the abilities and intentions of the project creators, as backers do not know whether the creators are trustworthy or credible (Moysidou, 2016). This is particularly true for projects that ask for large amounts of funding. For example, Mollick (2014) found that the great majority of Kickstarter projects deliver the promised rewards after a considerable delay, while some do not deliver at all. Another source of insecurity is related to the project outcome (Moysidou, 2016). Most projects, in particular from lending- and equity-based crowdfunding, are at a very premature stage and consist only of an idea, so that the quality of the expected outcome is not directly observable (Moysidou, 2016). In this environment of uncertainty herding plays a central role. Herding refers to as backers following the decisions of others when to decide whether or not to invest in a project (Herzenstein et al., 2011; Liu et al., 2014). Backers herd when they are uncertain about the decision to be made, as a result of having either incomplete or asymmetric private information (Herzenstein et al., 2011). Backers have to make their funding decisions based on limited information the project creators provide on the crowdfunding platform. As a result backers assume herding strategy because they believe that others are better informed than they are (Herzenstein et al., 2011). 
Uncertainty primarily entails reward-motivated backers, as they are motivated to invest in anticipation of a reward. That is why reward-motivated backers particularly chose the herd strategy. We believe that assuming herd behavior for these group of backers will have an effect on their motivation process. We propose that higher degrees of herding behavior in reward-motivated backers strengthen the association between their reward motivation and their investment behavior that is - because of the described unsecure environment - lower compared to situations in which security is well-balanced. This means that the motivation to invest for receiving a reward is not very strong. In this case herding probably will compensate the lost security and consequently strengthens the reward motivation. Against this background we predict that higher levels of herd behavior in reward-motivated backers will enhance the association between reward motivation and investment.

H8. In an incentive-based crowdfunding context, higher degrees of backers' herding behavior strengthen the association between reward motivation and investment.

The resulting research model of the seven types of motivation plus the concept of herding is summarized in Fig. 1.

\section{Methodology}

\section{Research setting}

We examine the equity-based online crowdfunding platform of Innovestment that connects project creators with project backers for financing start-ups. Innovestment focuses on high-tech companies and has already funded 127 start-ups with more than $€ 223$ million in total. Its technical platform is equipped with the same fundamentals we have discussed: i.e., UPWs for backers, a project collection page, as well as project pages that include all the above described features and functionalities. However, there is one exception. Unlike most incentive-based crowdfunding platforms, Innovestment's UPWs do not display the exact amount of money a backer has already funded.

\section{Measures}

Since perceived motivation in a certain situational context can best be expressed by the individuals themselves, we followed the approach by Grant and Berry (2011) and use self-reported data to measure different forms of employee motivations. The scales for each form of motivation allow respondents to rate their motivations on a Likert-type scale anchored at 1 ("strongly agree") and 5 ("strongly disagree"). We adopted this approach for our case to measure backers' motivation in the specific situational context of incentive-based crowdfunding on Innovestment. We developed seven scales of motivation (one per each type of motivation), each composed of three items. All 21 items were self-developed based on the rationale

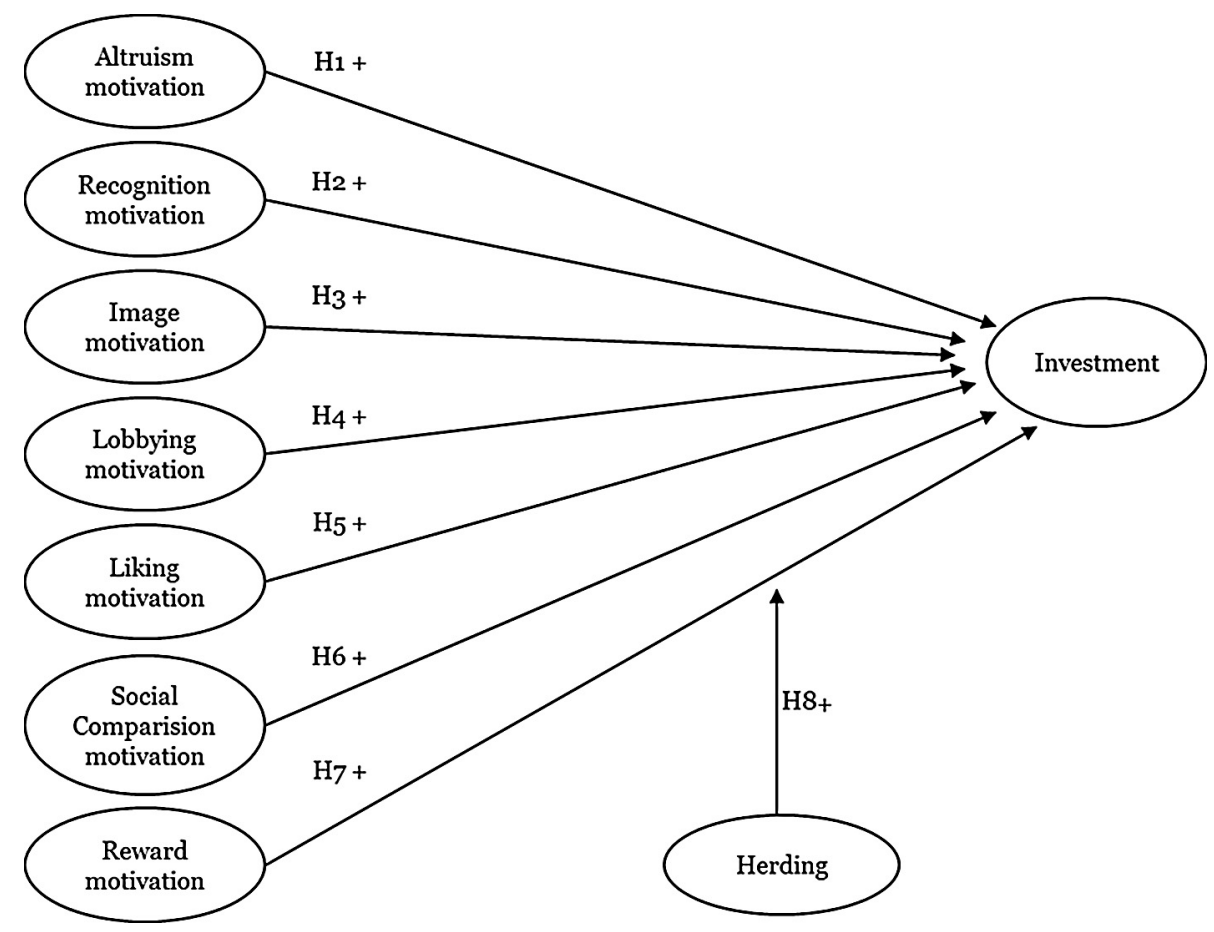

Fig. 1. Hypothesized research model. 
of Grant and Berry's (2011) research. All scales were operationalized reflectively, according to the approach of Grant and Berry (2011).

To measure herding behavior, we followed the approach by Sun (2013), who also investigated herding behavior as a moderator. He developed a research model to describe how herd behavior of IT-system-users impacts technology acceptance by these users. He found empirical evidence that the association between a user's belief about the usefulness of an IT-system (adjusted belief) and the user's perception that the IT-system is useful after its adoption (modified belief) is moderated by the user's herding behavior. To measure this moderator, he used a self-developed measure that expected users to self-assess their herding behavior with the help of three items, each using a five point Likert scale, where 1 indicates "strongly agree," 3 indicates "neutral," and 5 indicates “strongly disagree." Since Sun's (2013) herd measure has been validated and the context in which herd is measured is comparable to our situation, we adopted and adapted this instrument, including its inherent three items to measure backers' herd behavior. Following Sun's (2013) argument, we operationalized herd behavior reflectively.

Investment was measured by one item, reflecting the amount of average investment made by one investor. We measured investment in such a way as to express the degree of backers' behavior according to the above described Expectancy Theory of Motivation, which says that a higher intenseness of behavior results from higher degrees of motivation (Vroom, 1964). The amount of average investments was measured on a five-point scale. The scale was coded into categories, ranging from " $1 €$ to $999 €$ " to "5000 $€$ and more." Based on the rationale presented above, the investment variable was operationalized reflectively.

The Appendix A of this paper lists the measures utilized in this research.

\section{Procedure and sample demographics}

An online survey was conducted to examine the research model. The questionnaire was implemented using the online survey service, LimeSurvey. The questionnaire was structured, tested, and consequently adapted to the needs of the target audience. The questionnaire was also pre-tested by ten experts pursuing doctoral and master's degrees in information technology and business administration. The objectives of the pre-test were to ensure that none of the items were ambiguous and to confirm that the items adequately captured the domain of interest. The results of the pre-test indicated that the content of the items was valid.

For the survey, we used 995 all investors on the Innovestment website who had already funded at least one venture, independent of how long ago the previous time was. All these backers had contributed to different kind of start-ups projects and invested amounts ranging from $€ 300$ to $€ 15,500$ per project. Each of these investors was provided with a personalized link to the online survey by e-mail and invited to complete the survey online. In the five-week survey period, a total of 309 backers provided usable responses to the questionnaire, representing a $31 \%$ response rate.

Of the 309 backers in the sample, $95.8 \%$ were men $(n=296)$, which is typical for equity-like investments. The average age was 39 years, with a range of 20-60 plus. Their educational level was above average, with the vast majority (66\%) having a university degree, followed by a doctorate or a comparable education (17\%). In terms of professional status, most backers were employees (63\%) or self-employed (28\%) and the remaining were either students (6\%) or retirees (3\%). The majority (86\%) had additional investments, notably financial investments (84\%) and real investments (49\%); however, an exception was in start-ups. It can thus be assumed that the backers had investment experience. Furthermore, $60 \%$ of respondents also used Innovestment or other crowdfunding platforms to invest in start-ups. The majority (67\%) of backers had invested an average of $€ 1000$ - $€ 1499$ per share in a start-up, followed by an average investment share of $€ 5000$ and more per start-up (14\%). Almost as many (13\%) had invested $€ 1500-€ 2499$ per share, and only $5 \%$ between $€ 2500$ and $€ 4499$ per share in a start-up. Only a few (1\%) had invested an average amount of less than $€ 1000$.

\section{Common method variances}

To control for effects - such as socially desirable responses (Paulhus, 2002) - in the questionnaire, we assured respondents that there were no wrong answers and asked them to answer questions as honestly as possible (Podsakoff et al., 2003). Afterwards, we conducted the Harmann's Single Factor Test (Podsakoff et al., 2003). We performed an exploratory factor analysis with all the model indicators and examined the unrotated factor solution. Because more than one factor emerged and the first factor does not account for the majority of covariance among the measures, common method variances should not be a major problem within this study (Podsakoff et al., 2003).

\section{Model evaluation and results}

\section{Method}

To estimate structural equation models, one can use covariance-based methods (Bollen, 1989; Jöreskog, 1977) or the variance-based PLS approach (Henseler and Ringle, 2009; Lohmüller, 1989). We applied the PLS approach because its formal premises embody a greater range of flexible applications for reflective constructs (Lohmüller, 1989). As the objective of our analysis was to determine the impact of motivations that can be best measured by reflective measurement models, the PLS 
approach emerged as being most suitable. Furthermore, we chose this approach because it was more suitable for identifying key driver constructs than covariance-based approaches (Hair et al., 2011).

The statistical software application, SmartPLS 2.0 (Ringle and Wende, 2005), was used to compute the PLS path model.

Next, we present the results in three steps: (1) we describe the results of the reflective measurement model assessment; (2) we discuss the estimation results of the basic model; and (3) we test the hypotheses and examine the interaction effect.

\section{Assessment of the reflective measurement model}

Reliability has been met with regard to the reflective measurement model for the exogenous latent variables, the motivations, and the endogenous variable "Investment". First, all factor loadings, except SC1 (0.626), lie well above Hulland's (1999) suggested threshold value of 0.7. However, according to Hair et al. (2011), single factor loadings between 0.4 and 0.7 are considered to be acceptable and thus the indicator "SC1" was retained in the model. The indicators "Altruis1," "Recog2", and "Reward3" were eliminated from the original model due to small and non-significant charges to the respective construct. Second, for all constructs, the values for the composite reliability are well above the required limit value of 0.6 , and thus the construct internal consistency in total is very good (Hair et al., 2012; Henseler and Fassott, 2010) (see Table 1).

We further assessed convergent validity by calculating the average variance extracted (AVE). All calculated AVE values exceed the required minimum value of 0.5 (Hair et al., 2012; Henseler and Ringle, 2009).

We tested discriminant validity with the help of the Fornell-Larcker criterion, which claims that one factor's AVE should be higher than its squared correlation with every other factor (Fornell and Larcker, 1981). As shown in Table 2, the diagonal elements (AVE) exceeded other entries (squared correlations) in the same row or column, thus satisfying the discriminant validity requirement.

With the examined quality criteria, the established reflective measurement models of the latent constructs are confirmed empirically in the context of PLS and are thus suitable for further analysis of the structural model.

\section{Assessment of the structural model}

In general, the most important criterion for the assessment of the structural model is the coefficient of determination, $\mathrm{R}^{2}$. According to Chin, while an $\mathrm{R}^{2}$ of 0.67 for latent endogenous variables in a structural model can be considered as "substantial" and an $\mathrm{R}^{2}$ of 0.33 as "moderate", $\mathrm{R}^{2}$ should always be higher than 0.19 (Chin, 1998). Thus, with a value of 0.2466 , as illustrated in Table 3, the $\mathrm{R}^{2}$ of our endogenous latent variable "Investment" lies at an acceptable level.

The Stone-Geisser criterion, Q2, is established using the blindfolding procedure to compute cross-validated redundancy (Henseler and Ringle, 2009). In our analysis, the Q2 value is above the threshold value of zero. All variables exhibit relatively poor effect size and prognosis relevance; however, they are still of acceptable quality.

The process of verifying relevant assessment criteria with respect to the PLS approach is concluded at this point. Our analysis indicates that all measures used are reliable and valid.

Table 1

Results of the reflective measurement model.

\begin{tabular}{|c|c|c|c|c|}
\hline Variable & Indicators & $\begin{array}{l}\text { Indicator } \\
\text { reliability }(>0.7)\end{array}$ & $\begin{array}{l}\text { Average variance } \\
\text { extracted (AVE) }(>0.5)\end{array}$ & $\begin{array}{l}\text { Composite } \\
\text { reliability }(>0.6)\end{array}$ \\
\hline Altruism & $\begin{array}{l}\text { Altruis1 } \\
\text { Altruis2 } \\
\text { Altruis3 }\end{array}$ & $\begin{array}{l}\text { Eliminated } \\
0.863 \\
0.964\end{array}$ & 0.835 & 0.911 \\
\hline Recognition & $\begin{array}{l}\text { Recog1 } \\
\text { Recog2 } \\
\text { Recog3 }\end{array}$ & $\begin{array}{l}0.985 \\
\text { Eliminated } \\
0.785\end{array}$ & 0.794 & 0.884 \\
\hline Image & $\begin{array}{l}\text { Image1 } \\
\text { Image2 } \\
\text { Image3 }\end{array}$ & $\begin{array}{l}0.982 \\
0.957 \\
0.883\end{array}$ & 0.887 & 0.959 \\
\hline Lobbying & $\begin{array}{l}\text { Lob1 } \\
\text { Lob2 } \\
\text { Lob3 }\end{array}$ & $\begin{array}{l}0.944 \\
0.830 \\
0.858\end{array}$ & 0.772 & 0.910 \\
\hline Liking & $\begin{array}{l}\text { Like1 } \\
\text { Like2 } \\
\text { Like3 }\end{array}$ & $\begin{array}{l}0.845 \\
0.935 \\
0.941\end{array}$ & 0.824 & 0.934 \\
\hline Social Comparison & $\begin{array}{l}\text { SC1 } \\
\text { SC2 } \\
\text { SC3 }\end{array}$ & $\begin{array}{l}0.626 \\
0.737 \\
0.993\end{array}$ & 0.640 & 0.837 \\
\hline Reward & $\begin{array}{l}\text { Rew1 } \\
\text { Rew2 } \\
\text { Rew3 }\end{array}$ & $\begin{array}{l}0.866 \\
0.954 \\
\text { Eliminated }\end{array}$ & 0.830 & 0.907 \\
\hline
\end{tabular}


Table 2

Results of the discriminant test (Squared Correlations and AVEs).

\begin{tabular}{|c|c|c|c|c|c|c|c|}
\hline$\underline{\text { AVE }}$ & Altruism & Recogn. & Image & Lobbying & Liking & S. Com. & Reward \\
\hline Altruism & $\underline{0.835}$ & & & & & & \\
\hline Recogn. & $\overline{0.0059}$ & $\underline{0.794}$ & & & & & \\
\hline Image & 0.0004 & 0.0088 & $\underline{0.887}$ & & & & \\
\hline Lobbying & 0.0643 & 0.0163 & 0.0656 & $\underline{0.772}$ & & & \\
\hline Liking & 0.0028 & 0.0797 & 0.2127 & 0.0624 & 0.824 & & \\
\hline S. Com. & 0.0476 & 0.1143 & 0.1720 & 0.0943 & 0.1227 & $\underline{0.640}$ & \\
\hline Reward & 0.0092 & 0.0260 & 0.0905 & 0.0194 & 0.0201 & 0.0141 & $\underline{0.830}$ \\
\hline
\end{tabular}

Table 3

Results for evaluation of the structural model.

\begin{tabular}{|c|c|c|c|}
\hline & & $\mathrm{f}^{2}$ & $\mathrm{q}^{2}$ \\
\hline Altruism & & 0.134 & 0.175 \\
\hline Recognition & & 0.170 & 0.177 \\
\hline Image & & 0.223 & 0.189 \\
\hline Lobbying & & 0.187 & 0.198 \\
\hline Liking & & 0.154 & 0.146 \\
\hline Social comparison & & 0.118 & 0.112 \\
\hline Reward & & 0.106 & 0.129 \\
\hline \multirow[t]{2}{*}{ Investment } & $\mathrm{R}^{2}$ & 0.247 & \\
\hline & $Q^{2}$ & 0.242 & \\
\hline
\end{tabular}

Table 4

Results for bootstrapping procedure of the structural model.

\begin{tabular}{|c|c|c|c|c|}
\hline & Original sample $(\geq+0.1 ; \leq-0.1)$ & Sample mean (M) & Standard error (STERR) & T-values \\
\hline Altruism > Investment & -0.188 & -0.166 & 0.1434 & $1.3114^{\text {n.s. }}$ \\
\hline Recognition > Investment & -0.2574 & -0.209 & 0.1449 & $1.7765^{*}$ \\
\hline Image $>$ Investment & 0.3809 & -0.262 & 0.2218 & $1.7172^{*}$ \\
\hline Lobbying > Investment & 0.2853 & 0.2772 & 0.1381 & $2.0661^{* *}$ \\
\hline Liking > Investment & 0.2633 & 0.241 & 0.1538 & $1.7117^{*}$ \\
\hline Social Comparison > Investment & 0.1406 & 0.041 & 0.1832 & $0.7671^{\text {n.s. }}$ \\
\hline Reward > Investment & 0.1989 & -0.073 & 0.1568 & $2.5805^{* * *}$ \\
\hline \multicolumn{5}{|l|}{ Moderating Effect } \\
\hline Reward ${ }^{*}$ Herding > Investment & 0.3735 & -0.2545 & 0.7093 & $2.5266^{* * *}$ \\
\hline
\end{tabular}

n.s.: not significant.

Significant at the $\mathrm{p}<0.01$ level $(\mathrm{T} \geq 2.57)$

** Significant at the $\mathrm{p}<0.05$ level $(\mathrm{T} \geq 1.96)$

* Significant at the $\mathrm{p}<0.1$ level $(\mathrm{T} \geq 1.65)$.

\section{Hypotheses testing}

We applied a nonparametric bootstrapping procedure (5000 samples; 83 cases; no sign change) to evaluate path coefficients and their significance (Henseler et al., 2009).

Determinants achieve acceptable path coefficients if values are equal to or exceed the criterion of 0.2 (absolute value) (Huber and Herrmann, 2007). The results of our bootstrapping analysis (see Table 4) are between 0.257 and 0.381 (absolute values), with good values for the path coefficients of the motives "Recognition", “Lobbying", "Image", and "Liking”. The path coefficient of the variable "Reward" receives an almost acceptable value.

Results are provided in Table 4. The results of the bootstrapping analysis, indicating good values for the path coefficients of the motives "Recognition," "Lobbying," "Image" and "Liking," are between 0.257 and 0.381 (absolute values), according to Huber et al.'s recommendation, which deems that determinants achieve acceptable path coefficients if values are equal to or exceed the criterion of 0.2 (absolute value) (Huber and Herrmann, 2007). The path coefficient of the variable "Reward" receives an almost acceptable value.

As Table 4 shows, "Recognition" exerts a significant negative influence on "Investment" (on a p $<0.1$ level). The impact of the variable "Image" is positive and significant on a $\mathrm{p}<0.1$ level. The impact of the motive "Lobbying" is also positive and significant (on a p $<0.05$ level), as well as the impact of the "Liking" motive (on a $\mathrm{p}<0.1$ level). "Return" can be interpreted also to be positive and significant (on a p $<0.01$ level). Hence, the results provide full support for hypotheses 3 (Image), 4 (Lobbying), 5 (Liking), and 7 (Return). With respect to hypothesis 2 (Recognition), a significant relationship on investment is revealed, but this relationship is negative, contrary to the hypothesized relation. 
Our results show insufficient evidence for significant influence for the motivation "Social Comparison." Furthermore, our results indicate that the impact of the motive "Altruism" is negative and non-significant. Thus, hypotheses 1 and 6 receive no support.

\section{Assessment of the moderating effect}

To test the moderating effect of herding, we applied the PLS product indicator approach (Chin et al., 2003). According to Baron and Kenny (1986), the investigation of a moderator influence occurs by the formation of an indicator variable, which results from the multiplication of the indicators of exogenous variables and the indicators of moderator variables. Hence, reward (predictor) and herding (moderator) are multiplied to create an interaction variable (reward $*$ herding) to predict investment (Chin et al., 2003). To test the moderating effect, we have estimated the influence of predictor on criterion variable, the direct impact of the moderating variable on the criterion variable, and the influence of interaction variable on criterion variable. In general, the significance of our moderator can be confirmed if the interaction effect is meaningful. This means that for assessing the moderating effect, the path coefficient of the interaction variables is crucial (Baron and Kenny, 1986), independent of the size of the path coefficients of the two other influences (Henseler and Fassott, 2010).

In our case, we have estimated a standardized path coefficient of 0.3735 for the interaction variable, which is significant at $\mathrm{p}<0.05(\mathrm{t}=1.96)$. To estimate significance of the path coefficient, we applied a nonparametric bootstrapping procedure. The results show that the beta changes are significant $(\beta=0.3735, t=2.5266)$. Consequently, we confirm that herding moderates the relationship between reward and investment, and we confirm $\mathrm{H} 8$.

\section{Discussion}

The purpose of this study was to explore backers' motivation for investing in projects of incentive-based crowdfunding. Our results show that backers are motived to make an investment by the following: (1) to receive recognition from others in return for their investment (recognition motivation); (2) to influence certain projects to fruition (Lobbying motivation); (3) to create an online image (image motivation); (4) because they simply like a venture (liking motivation); and (5) in anticipation of a return or reward (reward motivation). Furthermore, (6) backers' reward motivation is enhanced by their herding behavior.

Our results reveal that the recognition motive has a significant effect on investment but, contrary to our hypothesized relation, this relationship is negative. This result can be interpreted as follows. On most crowdfunding platforms, the names of funders are prominently displayed on the project page and in some cases also the amount of money they have given. However, the sum of money the funders gave is not displayed on the Innovestment website. Against this background, recognition-motivated backers in Innovestment could expect to receive recognition from third parties regardless of the amount of money they funded. The backers who participated in our survey act as homo economicus and fund only low amounts of money, knowing they would achieve exactly the same recognition effect as with a higher amount of money. This is in contrast to open source communities where software programmers are associated with the quality of their contributions. For example, Hars and Ou (2002) purport that recognition-motivated participants of open source software communities only expect recognition from others when their contributed software code meets a certain quality standard, since their contributions are branded with their name and thus can be easily brought into connection with their person.

Our results reveal that backers in incentive-based forms of crowdfunding have no altruism motive. This is contrary to the results of the study by Galak et al. (2011). In their study of microlending (a sub-form of lending-based crowdfunding) decision making, the authors found that a microlender's decision to fund incorporates aspects of both traditional investment decision making (reward) and psychological factors that influence charitable-giving (altruism) decisions (Galak et al., 2011). The reason for our differing results might be that crowdfunded microlending differs from traditional lending-based crowdfunding. In microfinancing, traditionally, small loans are made to small businesses and entrepreneurs in developing countries. This enables individual lenders to make small, uncollateralized loans to individual entrepreneurs and small businesses in need and has therefore emerged as a leading effort to alleviate world poverty (Galak et al., 2011). This charitable character is a constituent aspect of microlending, while it is not an aspect of lending-based or incentive-based crowdfunding per se. Therefore, crowdfunded microfinancing has to be seen in a much more prosocial light; in which helping others or altruism constitutes a significant motive of microlenders by definition. However, our results have to be seen and interpreted against the background of traditional lending-based crowdfunding.

\section{Conclusion}

\section{Theoretical contribution}

Research on backers' motivations for participation in incentive-based crowdfunding is at an embryonic stage and understanding of the motivation for participation in incentive-based crowdfunding is incomplete. Therefore, we conducted our study. We report empirical evidence for some new motives that constitute relevant drivers for funding. We found that, among other motivations, backers fund because: (1) they expect to receive recognition from others in return for their investment (recognition motive); (2) they want a certain project to be realized (lobbying motive); (3) they like a certain venture 
(liking motive); and (4) they want to be liked or well-regarded by others (image motive). By theoretically deriving and empirically validating these four new basic motives, we expand the list of known motives. By doing so, we not only answer ongoing calls to investigate crowd's motivation for participation in crowdfunding (Lehner, 2013; Moritz and Block, 2013), but also contribute by significantly enhancing the existing body of knowledge.

As outlined, the existing body of knowledge on motivation for backers' participation in incentive-based crowdfunding suggests that backers are mainly egoistically motivated and do not seem to have prosocial motives (Berglin and Strandberg, 2013; Gerber and Hui, 2013; Ryu and Kim, 2014). This common mindset goes hand in hand with ancient psychological assumptions that prosocial motives and self-interested motives involve mutually exclusive or opposing desire (Batson, 1998; Meglino and Korsgaard, 2004; Schwartz and Bardi, 2001). However, recent results from motivation psychology research indicates that prosocial and self-interested motives can co-exist (De Dreu and Nauta, 2009). Our study supports this. We found evidence that backers in incentive-based crowdfunding not only have self-interested motives (e.g., recognition, lobbying, and image), but are also motivated to fund because they simply like a certain venture (liking motive), which clearly represents a prosocial motive that does not have an egoistic background. So backers in incentive-based crowdfunding weigh both the egoistic factors germane to potential future rewards, image, recognition, etc., as well as the prosocial factors germane to feelings of liking others. Therefore, our research contributes not only by acknowledging the modern "coexistence" theory in motivation psychology but also by being the first to empirically validate that backers' funding decisions are also based on prosocial motives. By doing so, we significantly enrich the body of knowledge through broadening and specifying the understanding of motivation for participation in incentive-based crowdfunding.

The herding phenomenon is prominently discussed in crowdfunding literature. For example, Herzenstein et al. (2011) and Lee and Lee (2012) show that the more existing funding a loan has, the more likely this loan will receive future funding. Furthermore, Zhang and Liu (2012) show that lenders on Prosper Marketplace (an online lending platform) not only use existing bidding amounts as herding signals, but also view such signals as being more informative when the underlying loan has unfavorable characteristics. Krumme and Herrero (2009) present simulations of different scenarios of herding behavior and reciprocity in an attempt to explain the observed bidding patterns of lenders. In a large sample of daily data from one of the largest P2P lending platforms in Korea, Lee and Lee (2012) show strong evidence of herding and its diminishing marginal effect as bidding advances. In sum, existing studies on herding behavior in crowdfunding scenarios have focused on either providing evidence for its occurrence or on exploring which factors influence and/or strengthen the phenomenon. However, the impact of herd behavior on other phenomenons, such as the motivation of backers, so far has been neglected. Complementing this research gap, our study is the first to provide evidence for herd behavior's reinforcing impact on the association between backers' reward motivation and investment. This not only underpins the understanding of reward motivation of backers in incentive-based forms of crowdfunding, but also enhances the body of knowledge on herding in crowdfunding scenarios at all.

\section{Implications for practice and IS research}

As outlined, we have found evidence of motivations that sufficiently and specifically explains why the crowd invests in projects on incentive-based crowdfunding systems. These motivations provide valuable insight not only for IS researchers who examine how human behaviors inform the design and use of web-based information systems, but also for managers of incentive-based crowdfunding platforms. IS researchers and operators may draw on our findings to systematically design or redesign and test specific and customized incentives. According to our motivation model, these incentives can stimulate backers' reward-, lobbying-, image-, liking- and recognition-motivation, and thereby lead to an investment. For example, a corresponding incentive to these motivations could be a more detailed UPW that not only displays backers' earlier investments but also the exact amount they funded for each investment. Such detailed information specifically would correspond to the image-motivation, since this information would help to build a backer's image. This design element could stimulate a backer's desire to create an online image (image-motivation), and once the image motivation has become activated, it will lead to an investment. Another design element could be a project presentation with a strong emotional binding force and strong persuasive power that could activate backers' liking motive.

While all crowdfunding platforms prominently display the name of the backers, not all display the amount of money the backers has given. Our study reveals that under these circumstances, recognition-motived backers can expect to receive recognition from third parties regardless of the amount of money they fund, therefore prompting them to give only small amounts of money. One lesson that can be drawn from this is that not only backers' names but also the amount of money they have funded should be displayed. This will prompt recognition-motivated backers to fund larger amounts of money in order to receive recognition from third parties. This principle successfully works in the case of open software communities. For example, Hars and Ou (2002) report that recognition-motivated participants of open source software communities only expect recognition of others when their contributed software code meets a certain quality level, since their contributions are branded with their name and thus can be easily brought into connection with their person.

As our survey reveals, herding behavior strengthens reward motivated backers' motivation to fund. In this regard, a recommendation system may be an effective instrument for crowdfunding systems. Recommendation systems are used widely in many online environments, including online retailing, Internet advertisements, mobile device applications, social networks, and other major areas that involve personal transactions and communications (Li and Karahanna, 2015). Amazon is a well-known e-vendor that successfully applies different types of recommendation systems. After a consumer views 
or purchases an item on Amazon, the website provides the consumer with recommendations similar to the item just viewed or purchased. Furthermore, the website provides additional recommendations in the "customer who bought this item also bought" section. A recommendation system on a crowdfunding platform could provide reward motivated backers with tailored recommendations for projects, in which many other backers have already invested. These recommendations might ease these backers' search for projects they are willing to fund. These are just a few examples of design elements that are relevant for both IS researchers and crowdfunding practitioners and that should be designed and tested in the future.

\section{Limitation}

Our survey has the specific limitation involving the sample of our motivation survey. The sample size was relatively small. Although the size was sufficient for applying structural equation modeling with the partial least square approach, our results would be more meaningful with a larger sample size. Future research should test and validate the model by collecting more data sets as well as data from a different composition of subjects consisting of different investors.

\section{Appendix A}

Altruism (self-developed)

Altruis1 I want to help people with good ideas on Innovestment without expecting any compensation

Altruis2 I like doing something for project initiators on Innovestment at some cost to myself

Altruis3 I deeply enjoy helping others on Innovestment - even if I have to make sacrifices

Recognition (self-developed)

For my fundings...

Recog1 ...I want to receive recognition from other backers on Innovestment platform

Recog2 ...I am aiming at being recognized

Recog3 ...I hope to receive acknowledgement from project initiators on Innovestment

Image (self-developed)

Image 1 I want to impress others on Innovestment

Image2 I am aiming giving an impression to other backers on Innovestment

Image3 I want project initiators to have a positive image of me based on my behavior on Innovestment

Lobbying (self-developed)

Lob1 I lobby for some of the projects presented on Innovestment, since they match my unique and specific needs

Lob2 Since some projects on Innovestment reflect my personal need, I campaign for these projects to become realized

Lob3 I plead for some projects to become true, since these projects are highly valuable in my own context

Liking (self-developed)

Like1 In my eyes, there are some projects on Innovestment that have their own personal appeal. That is why I would like to support these projects in some way

Like2 I really like the idea behind some projects on Innovestment and, therefore, I would like to support these projects in any way

Like3 I would like to support some of the projects that I find particularly likeable

Social Comparison (self-developed)

SC1 I contribute to some of the projects in order to match the contributions of others that have already contributed to these projects

SC2 I see contributing to a project as a competition with other backers that contribute to the same project

SC3 I seek to contribute more to a project than other backers have

Reward (self-developed)

Rew1 I contribute to projects to get a reward

Rew2 I engage in some of the projects on Innovestment in prospect of a reward

Rew3 I aim at receiving rewards from projects I engage in on Innovestment

Herding (adapted from Sun (2013))

Herd1 I give money to a project in that many other already have invested in

Herd2 I follow others in deciding whether or not to contribute to a project

Herd3 I would invest in a project because many other backers have already contributed to it 


\section{References}

Agrawal, A., Catalini, C., Goldfarb, A., 2015. Crowdfunding: geography, social networks, and the timing of investment decisions. J. Econ. Manage. Strategy 24 (2), 253-274.

Ahlers, G.K.C., Cumming, D.J., Guenther, C., Schweizer, D., 2012. Signaling in equity crowdfunding. Entrepreneurship Theory Practice 39 (4), 955-980. http:// dx.doi.org/10.2139/ssrn.2161587.

Al-Jabri, I.M., Al-Khaldi, M.A., 1997. Effects of user characteristics on computer attitudes among undergraduate business students. J. End User Comput. 9 (2), $16-22$.

Ball, S., Eckel, C.C., 1998. The economic value of status. J. Socio-Econ. 27 (4), 495-514.

Baron, R.M., Kenny, D.A., 1986. The moderator-mediator variable distinction in social psychological research- conceptual, strategic and statistical considerations. J. Personal. Soc. Psychol. 51 (6), 1173-1182.

Batson, C.D. (Ed.), 1998. Altruism and Prosocial Behavior (Vol. 4). McGraw-Hill, New York.

Batson, C.D., Dyck, J.L., Brandt, J.R., Batson, J.G., Powell, A.L., 1988. Five studies testing two new egoistic alternatives to the empathy-altruism hypothesis. J. Pers. Soc. Psychol. 55 (1), 52-77.

Benkler, Y., Nissenbaum, H., 2006. Commons-based peer production and virtue. J. Polit. Philos. 14 (4).

Berglin, H., Strandberg, C., 2013. Leveraging Customers as Investors: The Driving Forces Behind Crowdfunding. Uppsala University, Working Paper, Available at <http://www.crowdsourcing.org/document/leveraging-customers-as-investors-the-driving-forces-behind-crowdfunding-/23974>.

Bollen, K.A., 1989. Structural Equations with Latent Variables. Wiley-Interscience, New York.

Bretschneider, U., Leimeister, J.M., Mathiassen, L., 2015. IT-enabled product innovation: customer motivation for participating in virtual idea communities. Int. J. Prod. Dev. 20 (2), 126-141.

Brettel, M., 2003. Business angels in Germany: a research note. Venture Capital 5 (3), 251-268. http://dx.doi.org/10.1080/1369106032000122095.

Broos, A., 2005. Gender and information and communication technologies (ICT) anxiety: male self-assurance and female hesitation. Cyber Psychol. Behav. 8 (1), 21-31.

Chen, P., Garcia, S.M., 2010. Yin and Yang Theory of Competition: Social Comparison and Evaluation Apprehension Reciprocally Drive Competitive Motivation. Available at <http://deepblue.lib.umich.edu/bitstream/handle/2027.42/77608/patchen.pdf?sequence=1> Working Paper University of Michigan.

Chin, W.W. (Ed.), 1998. The Partial Least Squares Approach to Structural Equation Modeling. Modern Methods for Business Research. Lawrence Erlbaum, New Jersey.

Chin, W.W., Marcolin, B.L., Newsted, P.R., 2003. A partial least squares latent variable modeling approach for measuring interaction effects: results from a monte carlo simulation study and an electronic-mail emotion/adoption study. Inform. Syst. Res. 14 (2), 189-217.

Clark, A.J., 2010. Empathy and sympathy: therapeutic distinctions in counseling. J. Mental Health Counsel. 32 (2), $95-101$.

De Dreu, C.K.W., Nauta, A., 2009. Self-interest and other-orientation in organizational behavior: implications for job performance, prosocial behavior, and personal initiative. J. Appl. Psychol. 94, 913-926.

Deci, E.L., Ryan, R.M., 1985. Intrinsic Motivation and Self-Determination in Human Behavior. Springer, Heidelberg.

Feeney, L., Haines, G.H., Riding, A.L., 1999. Private investors' investment criteria: Insights from qualitative data. Venture Capital 1 (2), 121-145. http://dx.doi. org/10.1080/136910699295938.

Festinger, L., 1954. A theory of social comparison processes. Human Relat. 7 (2), 117-140.

Fornell, C., Larcker, D.F., 1981. Evaluating structural equation models with unobservable variables and measurement error. J. Mark. Res. 18 (1), 39-50.

Frey, B., Meier, S., 2004. Social comparisons and pro-social behavior: testing conditional cooperation in a field experiment. Am. Econ. Rev. 94 (5), 17171722.

Galak, J., Small, D., Stephen, A.T., 2011. Microfinance decision making: a field study of prosocial lending. J. Mark. Res. $48,130-137$.

Gerber, E.M., Hui, J., 2013. Crowdfunding: motivations and deterrents for participation. ACM Trans. Comput.-Human Interact. 20 (6).

Gierczak, M.M., Bretschneider, U., Haas, P., Blohm, I., Leimeister, J.M., 2015. Crowdfunding: outlining the new Era of fundraising. In: Brüntje, D., Gajda, O. (Eds.), Crowdfunding in Europe: State of The Art in Theory and Practice. Berlin et al.: Springer Science \& Business Media.

Goffman, E., 1959. The Presentation of Self in Everyday Life. Doubleday, New York.

Grant, A.M., Berry, J.W., 2011. The necessity of others is the mother of invention: intrinsic and prosocial motivations, perspective taking, and creativity. Acad. Manag. J. 54 (1), 73-96.

Hair, J.F., Ringle, C.M., Sarstedt, M., 2011. Pls-Sem: Indeed a Silver Bullet. J. Market. Theory Pract. 18 (2), $139-152$.

Hair, J.F., Sarstedt, M., Ringle, C.M., Mena, J.A., 2012. An assessment of the use of partial least squares structural equation modeling in marketing research. J. Acad. Mark. Sci. 40, 414-433.

Hars, A., Ou, S., 2002. Working for Free? Motivations for participating in open source projects. Int. J. Electron. Commerce 6 (3), $25-39$.

Henderson, R., Deane, F., Barrelle, K., Mahar, D., 1995. Computer anxiety: correlates, norms and problem definition in health care and banking employees using the Computer Attitude Scale. Interact. Comput. 7 (2), 181-193.

Henseler, J., Fassott, G., 2010. Testing moderating effects in PLS path models: an illustration of available procedures. In: Esposito Vinzi, V., Chin, W.W., Henseler, J., Wang, H. (Eds.), Handbook of Partial Least Squares. Springer, Heidelberg.

Henseler, J., Ringle, C.M., 2009. The use of partial-least-squares path modeling in international marketing. In: Sinkovics, R.R., Ghauri, P.N. (Eds.), Advances in International Marketing. Emerald Group Publishing, pp. 277-319.

Henseler, J., Ringle, C.M., Sinkovics, R.R., 2009. The use of partial-least-squares path modeling in international marketing. In: Sinkovics, R.R., Ghauri, P.N. (Eds.), Advances in International Marketing, vol. 20. Emerald Group Publishing, pp. 277-319.

Herzenstein, M., Dholakia, U.M., Andrews, R.L., 2011. Strategic herding behavior in peer-to-peer loan auctions. J. Interact. Market. 25 (1), $27-36$.

Hoch, D., Roeding, C., 1999. Secrets of Software Success. Harvard Business School Press, Boston.

Hockenbury, D.H., Hockenbury, S.E., 2003. Psychology. Worth Publishers, New York.

Huber, F., Herrmann, A., 2007. Kausalmodellierung Partial Least Squares: Eine Anwendungsorientierte Einführung. Gabler, Wiesbaden.

Hulland, J., 1999. Use of Partial Least Squares (Pls) in strategic management research: a review of four recent studies. Strateg. Manag. J. 20 (2), $195-204$.

Jabr, W., Mookerjee, R., Tan, Y., Mookerjee, V.S., 2014. Leveraging philanthropic behavior for customer support: the case of user support forums. MIS Quart. 38 (1), 187-208.

Jöreskog, K.G., 1977. Structural equation models in social sciences: specification, estimation and testing. Applications of Statistics. P. R. Krishnaiah, Amsterdam.

Kang, Y.-S., Kim, Y.J., 2006. Do visitors' interest level and perceived quantity of web page content matter in shaping the attitude toward a web site? Decis. Support Syst. 42, 1187-1202.

Kim, H.-W., Zheng, J.R., Gupta, S., 2011. Examining knowledge contribution from the perspective of an online identity in blogging communities. Comput. Human Behav. 27 (5), 1760-1770.

Korzaan, M.L., 2003. Going with the flow: Predicting online purchase intentions. J. Comput. Inform. Syst. 43 (4), 25-31.

Krumme, A.K., Herrero, S., 2009. Lending behavior and community structure in an online peer-to-peer economic network. In: Paper presented at the 12th IEEE International Conference on Computational Science and Engineering, Vancouver, BC.

Lakhani, K.R., Wolf, R.G., 2005. Why hackers do what they do: Understanding motivation and effort in free/open source software projects. In: Feller, J., Fitzgerald, B., Hissam, S., Lakhani (Eds.), Perspectives on Free and Open Source Software. MIT Press, Cambridge, pp. 3-22.

Lee, E., Lee, B., 2012. Herding behavior in online P2P lending: an empirical investigation. Electron. Commer. Res. Appl. 11 (4), $485-503$.

Lehner, O.M., 2013. Crowdfunding social ventures: a model and research agenda. Vent. Capital 15 (4), $289-311$. 
Lerner, J., Tirole, J., 2002. Some simple economics of open source. J. Ind. Econ. 52, 197-234.

Li, S.S., Karahanna, E., 2015. Online recommendation systems in a B2C E-commerce context: a review and future directions. J. Assoc. Inform. Syst. 16 (2), $72-$ 107.

Lian, J.W., Lin, T.M., 2008. Effects of consumer characteristics on their acceptance of online shopping: comparisons among different product types. Comput. Hum. Behav. 24 (1), 48-65.

Lin, M., Viswanathan, S., 2016. Home bias in online investments: an empirical study of an online crowdfunding market. Manage. Sci. 62 (5), $1393-1414$.

Liu, D., Brass, D., Chen, D., 2014. Friendships in online peer-to-peer lending: pipes, prisms, and relational herding. MIS Quart. 39 (3), $729-742$.

Lohmüller, J.B., 1989. Latent Variable Path Modeling With Partial Least Squares. Physica Verlag, Heidelberg.

Ma, M., Agarwal, R., 2007. Through a glass darkly: Information technology design, identity verification, and knowledge contribution in online communities. Inform. Syst. Res. 18 (1), 42-67.

Maslow, A.H., 1987. Motivation and Personality, Vol. 3. Harper, New York.

Mason, C., Stark, M., 2004. What do investors look for in a business plan?: A comparison of the investment criteria of bankers, venture capitalists and business angels. Int. Small Bus. J. 22 (3), 227-248. http://dx.doi.org/10.1177/0266242604042377.

Meglino, B.M., Korsgaard, M.A., 2004. Considering rational self-interest as a disposition: Organizational implications of other orientation. J. Appl. Psychol. 89, 946-959.

Mollick, E., 2014. The dynamics of crowdfunding: An exploratory study. J. Bus. Ventur. http://dx.doi.org/10.1016/j.jbusvent.2013.06.005.

Moritz, A., Block, J.H., 2013. Crowdfunding und Crowdinvesting: State-of-the-Art der wissenschaftlichen Literatur (Crowdfunding and Crowdinvesting: A Review of the Literature) Available at SSRN: <http://ssrn.com/abstract=2274141>. doi: <http://dx.doi.org/10.2139/ssrn.2274141>.

Moysidou, K., 2016. Motivations to contribute financially to crowdfunding projects. In: Salampasis, D., Mention, A.L. (Eds.), Open Innovation: Unveiling the Power of the Human Element: World Scientific Publishing.

Nerdinger, F.W., 2006. Motivierung. In: Schuler, H. (Ed.), Lehrbuch der Personalpsychologie. 2 ed. Hogrefe, Göttingen; Bern; Wien; Toronto; Seattle; Oxford; Prag, pp. 385-404.

Nov, O., 2007. What motivates Wikipedians? Commun. ACM 50 (11), 60-64.

Ordanini, A., Miceli, L., Pizzetti, M., 2011. Crowdfunding: transforming customers into investors through innovative service platforms. J. Service Manage. 22 (4), 443-470.

Ozinga, J.R., 1999. Altruism. Praeger, Westport; Conn..

Paulhus, D.L. (Ed.), 2002. Socially Desirable Responding: The Evolution of a Construct. Erlbaum, Mahwah, NJ.

Pavlou, P.A., Fygenson, M., 2006. Understanding and predicting electronic commerce adoption: An extension of the theory of planned behavior. MIS Quart. $30(1), 115-143$

Podsakoff, P.M., MacKenzie, S.B., Lee, J.Y., Podsakoff, N.P., 2003. Common method biases in behavioral research: a critical review of the literature and recommended remedies. J. Appl. Psychol. 88 (5), 879-903.

Raymond, E.S., 2001. The Cathedral \& the Bazaar: Musings on Linux and Open Source by an Accidental Revolutionary: O'Reilly Media.

Ringle, C.M., Wende, S., 2005. SmartPLS 2.0 (Beta), from <http://www.smartpls.de>.

Ryu, S., Kim, Y.-G., 2014. Dynamics of the Crowdfunding Platform: Crowdfunding Participation Model Development and Empirical Analysis: Available at SSRN: http://ssrn.com/abstract=2423315 or http://dx.doi.org/10.2139/ssrn.2423315.

Sabherwal, R., Jeyaraj, A., Chowa, C., 2006. Information system success: individual and organizational determinants. Manage. Sci. 52 (12), $1849-1864$.

Schater, D., 2011. Psychology: Catherine Woods.

Schwartz, S.H., Bardi, A., 2001. Value hierarchies across cultures: Taking a similarities perspective. J. Crosscultural Psychol. 32, 268-290.

Schwienbacher, A., Larralde, B., 2012. Crowdfunding of small entrepreneurial ventures. In: Cumming, D. (Ed.), The Oxford Handbook ENTREPRENEURIAL FINANCE. Oxford University Press, New York.

Sun, H., 2013. A longitudinal study of herd behavior in the adoption and continued use of technology. MIS Quart. 37 (4), $1013-1041$.

Unger, J.B., Johnson, C.A., Rohrbach, L.A., 1995. Recognition and liking of tobacco and alcohol advertisements among adolescents. Prev. Med. $24,461-466$.

Vroom, V.H., 1964. Work and Motivation. Wiley, New York.

Zhang, J., Liu, P., 2012. Rational herding in microloan markets. Manage. Sci. 58 (5), 892-912. 